\title{
Hallazgo en capa de un artefacto lítico y fauna extinta en la laguna Las Encadenadas (provincia de Buenos Aires, Argentina)
}

Antonio Austral $^{1}$

El yacimiento de Los Flamencos II comprende parte de la playa noroeste y tramo de la barranca costera de Las Encadenadas ${ }^{2}$, laguna bonaerense del Partido de Saavedra, al oeste de las Sierras de Curamalal. Fue descubierto en enero de 1972 y rindió materiales líticos y huesos fósiles en la superficie y en la estructura sedimentaria. La importancia de su problemática radica en que proporciona información referente a la posible coexistencia del hombre con fauna extinta en la región pampeana, y plantea la cronometría pleistocénica de la misma por primera vez en mucho tiempo.

\section{Los datos de la dispersión superficial}

La ergología rescatada en la amplia extensión de la playa comprende artefactos líticos y huesos fósiles.

Universidad Nacional del Uruguay. Montevideo, URUGUAY.

2 Las costas de la laguna y sus aledaños terrazados constituyen una localidad arqueológica en que se identifican ocho sitios en diferente situación altimétrica con respecto al espejo de la laguna: a) Sitios ubicados a mayor altitud de los que se excavó uno; carecen de cerámica y de puntas líticas de proyectil trifaciales aun cuando hay puntas unifaciales de mano; la fauna es autóctona, especialmente constituida por Lama sp. b) Un segundo conjunto de sitios se encuentra en posición altimétrica que coincide con la superficie de la barranca actual relacionándose con el presente nivel de la laguna; en formas medanosas muy degradadas o en suelos francamente arenosos de poca potencia cubiertos por un tapiz herbáceo se hallan sitios que se caracterizan por la presencia contextual de puntas líticas de limbo triangular apedunculadas muy delgadas y de un tamaño que oscila entre 4 y $1.5 \mathrm{~cm}$; cerámica, lisa y decorada (pintada y grabada), piedra pulida (bolas y manos de mortero). Las puntas aludidas son por su morfología y tamaño las que aparecen frecuentemente en el área en yacimientos recientes. c) Se encuentran asimismo materiales en capa en el frente de las barrancas. d) Finalmente se realizan hallazgos arqueológicos en la playa de la laguna. Los materiales no se hallan in situ y constituyen un agregado de diferente origen. No pueden considerarse sin más como asociación. En esta nota se hace referencia a los sitios c y d. Se podría presumir que $\mathrm{c}, \mathrm{a}, \mathrm{y}$ b se dieron en sucesión, lo que constituiría un ordenamiento cronológico cuyo fundamento último estaría en la tipología de las asociaciones. Es necesario encontrar argumentos de otra índole, puesto que las cronologías de base tipológica no son suficientes.
Los primeros incluyen, en la perspectiva de una tipología que hemos llamado "gestáltica", núcleos, percutores, raspadores, raederas, escotaduras, denticulados, puntas con una cara plana o unifaces, dos fragmentos de puntas bifaciales de morfología inédita en la región. Además objetos tales como "piedra con hoyuelo" (yunque), cuña doble de las denominadas en la región "raedera bipolar", los cuales apuntan a la existencia de la técnica de talla bipolar.

Los fósiles están constituidos por una placa de Glyptodon sp. $^{3}$ y un fragmento todavía no diagnosticado. Se encontraron en las proximidades del pie de la barranca desde donde arranca la dispersión de los artefactos señalados.

\section{Los datos en la estructura sedimentaria}

La estructura sedimentaria está formada desde abajo hacia arriba por ${ }^{4}$ :

a) Sedimentos esencialmente arenolimosos a arcilloarenosos de color castaño grisáceo. Estratificado. Espesor visible de 15 a $20 \mathrm{~cm}$ incrementado hacia el sur.

b) Sedimentos arenolimosos a limoarenosos de color gris-blanquecino. Espesor $1.70 \mathrm{~m}$. Dos partes distinguibles: inferior, de $1.20 \mathrm{~m}$ de espesor con laminación de ambiente lacustre, y superior de $0.50 \mathrm{~m}$ de espesor con una estratificación menos marcada.

c) Sedimento arenoso de textura de mediana a fina de origen ceólico y color gris. Suelo escasamente

3 Determinación debida al Dr. Rosendo Pascual, jefe de la División Paleontología de Vertebrados de la Facultad de Ciencias Naturales y Museo de La Plata.

4 El estudio geológico se debe a los geólogos F. Hidalgo y F. O. De Francesco, del Departamento de Geología de la Facultad de Ciencias Naturales y Museo de La Plata, que produjeron un "Informe Preliminar sobre la Geología de la laguna Las Encadenadas". 
desarrollado con formas medanosas degradadas superficiales.

En la parte inferior de c aparecieron Lama sp. y Dolichotis sp., y en la superior Glyptodon sp. (placas) (Figura 1). Por sobre $0.30 \mathrm{~m}$ del Glyptodonte se halló un artefacto lítico de contorno hexagonal en superficie, espesado hacia la base (Figura 2 a y d) y de ápice más delgado. El 70\% y 40\% de las caras superior e inferior, respectivamente, son naturales y poseen corteza (Figura $2 \mathrm{~b}$ y c), la mitad derecha posee las aristas regularizadas por percusión, la izquierda está adelgazada sobre la cara dorsal. La porción superior del especímen tiene como rasgo saliente una arista que forma ángulo saliente obtenido por lascados unifaciales. Por el anverso se advierten unos negativos limitados. El borde derecho (Figura 2b) es filoso y neto, sin señales de uso. Fabricado en argilita. Medidas: largo $98 \mathrm{~mm}$, ancho $77 \mathrm{~mm}$ y espesor máximo (hacia la base) 59 mm. Puede ser caracterizado como "partidor". La materia prima no es local y procedería de la provincia de La Pampa. ${ }^{5}$

Fue unánime la conclusión de que el artefacto y los restos fósiles están in situ, aunque la relación entre el Glyptodon y el partidor es indirecta. Puede establecerse contemporaneidad en términos del estrato de la estructura sedimentaria que los contiene.

\section{Diagnóstico y proposiciones}

El diagnóstico de locus para la relación "partidor"/ placas de Glyptodon sp. propone la contemporaneidad en términos de la estructura litoestratigráfica.

El diagnóstico de espécimen, como entidad arqueológica en relación con el paradigma original (Austral 1971), es prematuro por falta de disponibilidad de contexto industrial, aunque puede postularse la pertenencia a cualquiera de los estadios líticos precerámicos.

Los materiales hallados en la playa pueden provenir de la barranca actualmente en retroceso erosivo que ha revelado una capa fértil o a los diversos yacimientos con contextos bien diferenciados identificados en los alrededores.

5 Opinión del Dr. Andreis, del Museo de la Plata.
El nivel actual de la laguna resulta de un proceso de reducción del espejo, con cuyas antiguas dimensiones se vincula el estrato $\mathrm{C}$ atacado por el tallado erosivo que expone el material arqueológico y fósil. Sin poder establecer las causas de este cambio, es, sin embargo, probable la datación de la presencia humana en relación con aquel nivel más alto que el actual.

\section{El problema de la datación en la relación "partidor"/Glyptodon sp.}

En relación con la datación de la asociación artefacto y fauna fósil, se adopta una decisión criterial después de analizar cuidadosamente las alternativas geológica y paleontológica del diagnóstico.

El informe de los geólogos (Fidalgo y De Francesco 1972 Ms) antes citado afirma que los sedimentos pertenecen por sus caracteres físicos al "piso" Platense. Se plantea entonces la necesidad de explicar en este continente la presencia de Glyptodon sp. que, en términos generales, se considera que llega sólo al final del Lujanense y que aquí constituiría una supervivencia (Pascual et al. 1965: 190-191).

Desde el punto de vista paleontológico Glyptodon sp., Lama sp. y Dolichotis sp. (que aparecen en el estrato arqueológicamente fértil) forman parte de los agregados mamalógicos de las edades mamífero Ensenadense y Lujanense que datan del Meso y Neopleistoceno (Pascual et al. 1965). Mientras la primera especie se extinguió en la Edad Mamífero Lujanense, las otras dos perviven todavía.

El autor adopta el criterio paleontológico, por cuanto la adopción del geológico plantearía el problema adicional de la supervivencia de Glyptodon, problema colateral a la fenoménica arqueológica y que no puede ser resuelta en los términos de este yacimiento. Por tanto el criterio paleontológico es más económico.

\section{Síntesis}

El yacimiento arqueológico Los Flamencos II del sur de la provincia de Buenos Aires rindió materiales superficiales y enterrados, en especial un partidor lítico en relación con Glyptodon sp. en el mismo estrato. Documenta la contemporaneidad del hombre con fauna extinta en la región pampeana, vinculada a un nivel lagunar antiguo más alto que el actual. Siguiendo el criterio paleontológico, la 


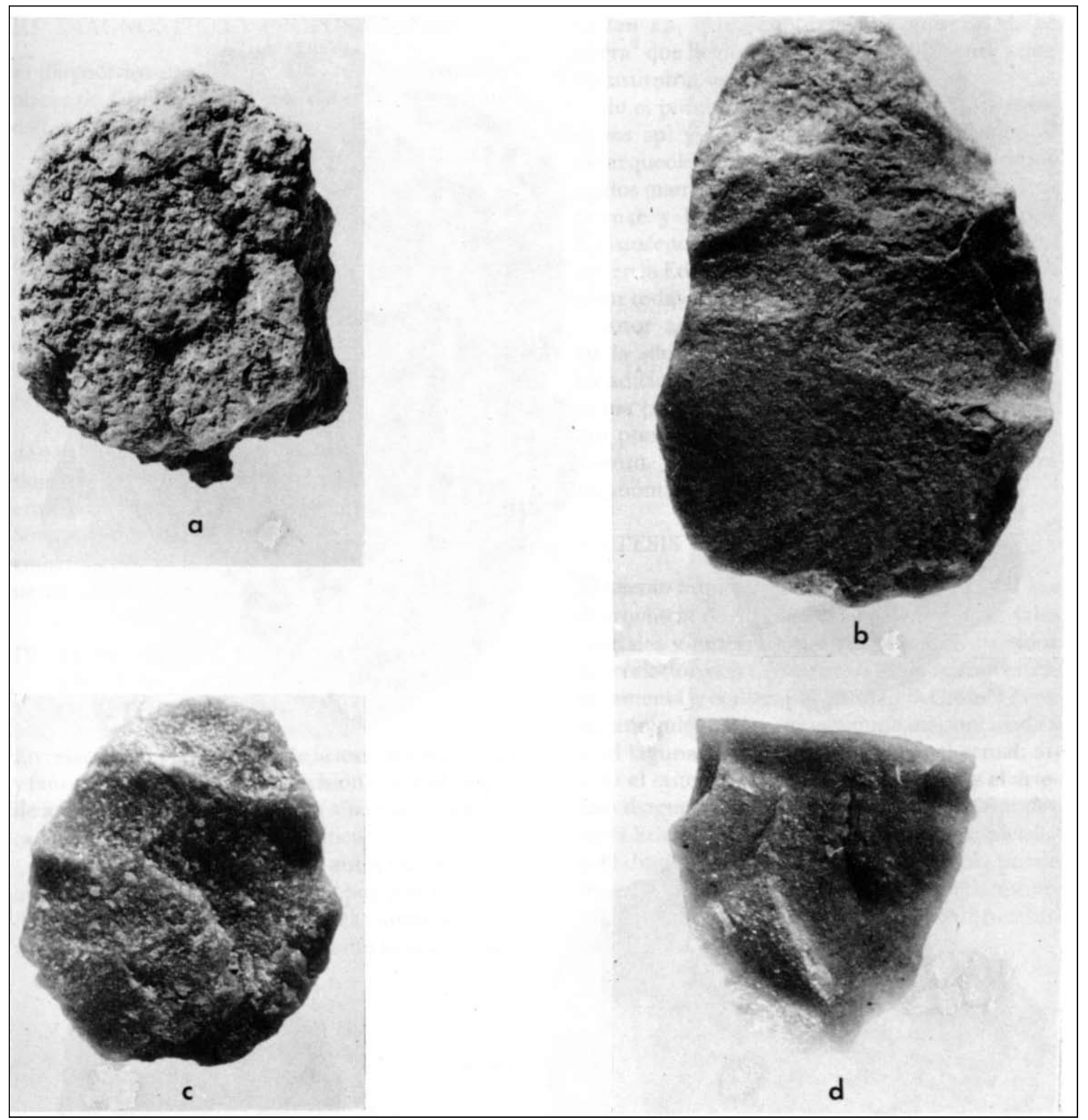

Figura 1. a) Placa de Glyptodon sp.; b) Cara ventral de un biface, los negativos ocupan preferentemente el lado derecho; c) Bifaz tosco. Es una preforma; d) Fragmento basal de una punta apedunculada, quebrada durante el perfeccionamiento de la forma en el proceso de retalla.

capa y el artefacto se diagnostican, por la presencia de Glyptodon sp., de la Edad Mamífero Lujanense del Neopleistoceno. El diseño de esta problemática, que sólo puede ser ajustado por la recolección de nuevos datos, replantea la profundidad temporal del poblamiento pampeano. 


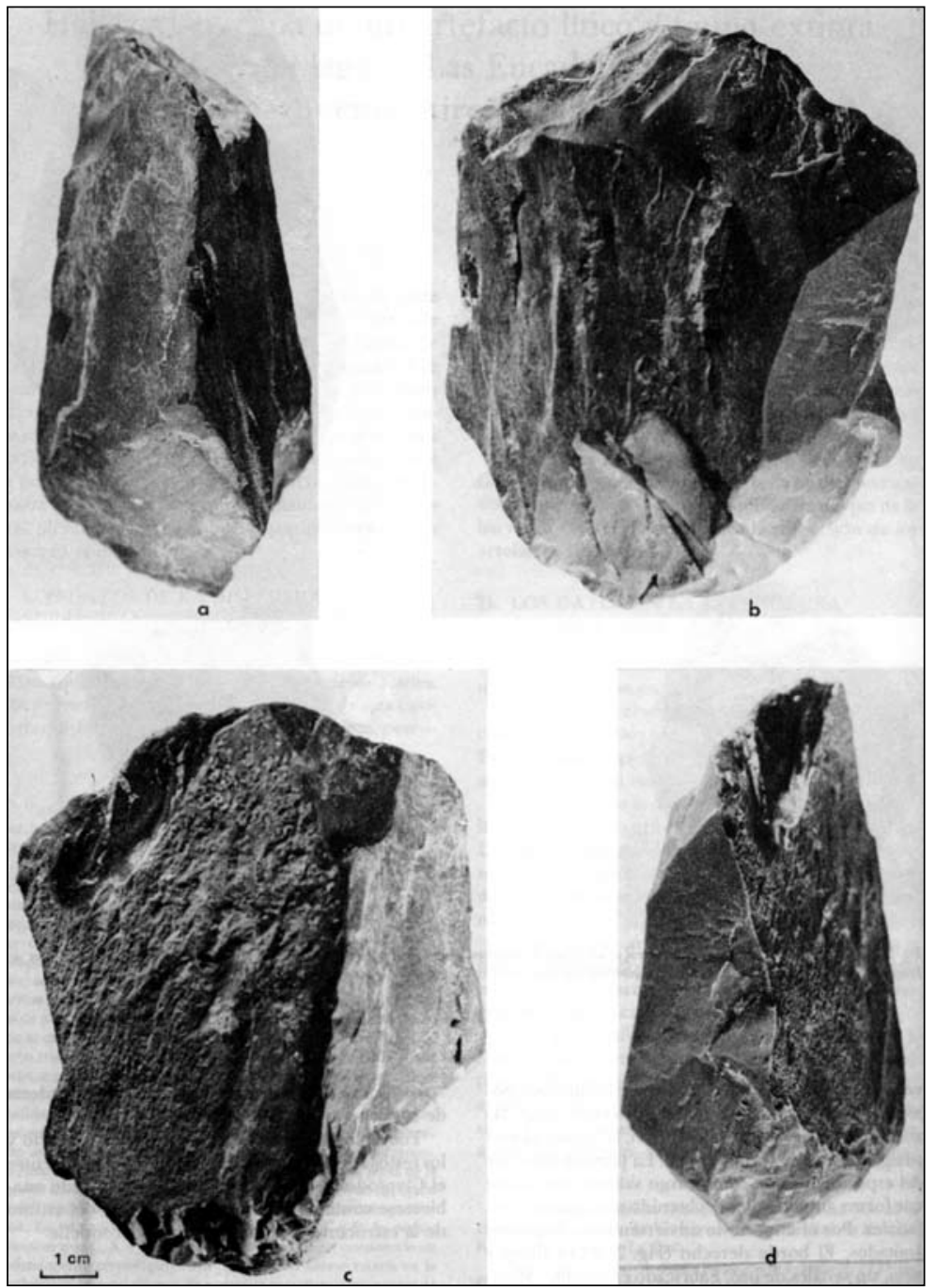

Figura 2. "Partidor" hallado en la misma capa geológica que el Glyptodon sp.

\section{REFERENCIAS CITADAS}

AUSTRAL, A., 1971. El yacimiento arqueológico de Vallejo en el noreste de la provincia de La Pampa. Contribución a la sistematización de la prehistoria y arqueología de la región pampeana. Relaciones de la Sociedad Argentina de Antropología V (2): 49 y ss.

1972. El yacimiento de Los Flamencos II. La coexistencia del hombre con fauna extinguida en la región pampeana. Relaciones de la Sociedad Argentina de Antropología VI.
FIDALGO, F. F. y O. DE FRANCESCO, 1972 Ms. Informe preliminar sobre la geología en la Laguna Las Encadenadas y sus vecindades.

PASCUAL, R.E. y J. ORTEGA, D. GONDAR y E. TONNI, 1965. Las Edades del Cenozoico mamalífero de Argentina con especial atención a aquellas del territorio bonaerense. Anales de la Comisión de Investigación Científica VI: 165 y ss. 